\title{
Reduced diversity and changed bacterioplankton community composition do not affect utilization of dissolved organic matter in the Adriatic Sea
}

\author{
Johanna Sjöstedtt ${ }^{1}$, Mikael Pontarp ${ }^{2}$, Tinkara Tinta ${ }^{3}$, Hanna Alfredsson ${ }^{1,5}$, \\ Valentina Turk ${ }^{3}$, Per Lundberg ${ }^{2}$, Åke Hagström ${ }^{1}$, Lasse Riemannn ${ }^{1,4, *}$ \\ ${ }^{1}$ Department of Natural Sciences, Linnaeus University, 39182 Kalmar, Sweden \\ ${ }^{2}$ Theoretical Population Ecology and Evolution Group, Department of Biology, Lund University, 22362 Lund, Sweden \\ ${ }^{3}$ Marine Biology Station, National Institute of Biology, 6630 Piran, Slovenia \\ ${ }^{4}$ Marine Biological Section, University of Copenhagen, 3000 Helsingør, Denmark \\ ${ }^{5}$ Present address: Department of Geology, Lund University, 22362 Lund, Sweden
}

\begin{abstract}
To obtain insights into the coupling between community composition, diversity and community function, bacterioplankton assemblages from the Gulf of Trieste (Northern Adriatic Sea) were exposed to increasing environmental stress throughout 2 wk in continuous seawater cultures to construct communities differing in composition and diversity. The assemblages were exposed to (1) decreased temperature, (2) decreased temperature and phosphate addition or (3) decreased temperature, phosphate addition and lowered oxygen level. Bacterial and viral abundances as well as bacterial community composition stabilized during the second week of the experiment. Denaturing gradient gel electrophoresis and pyrosequencing of 16S rRNA genes showed dramatic reductions in bacterial diversity in all treatments and major compositional differences relative to the inoculum. Nevertheless, no differences in the ability to exploit dissolved organic carbon (DOC) were found for the acquired communities relative to the inoculum, indicating that the bacterial communities were functionally redundant. We speculate that oscillations in exploitation of the DOC pool in situ are mainly governed by factors limiting the overall bacterial growth, rather than perturbations affecting only subsets of the microbial biota.
\end{abstract}

KEY WORDS: Diversity - Functional redundancy $\cdot$ Community structure $\cdot$ Continuous cultures · DOC

\section{INTRODUCTION}

Bacterioplankton community composition and diversity is known to vary geographically (Pommier et al. 2007) and over seasons (Murray et al. 1998, Reinthaler et al. 2005); however, the importance for community function and response to disturbance is poorly understood. Several studies have investigated the potential linkage between community composition and ecosystem function, but the results are conflicting. In most cases, microbial communities are sensitive to disturbance; however, microbial communities can re- spond in different ways without affecting ecosystem processes (reviewed by Allison \& Martiny 2008): microbial composition can be resistant and withstand disturbances without any change in composition (Bowen et al. 2011), the community can be resilient and quickly recover to the original composition (Shade et al. 2011, Werner et al. 2011), or the community can be functionally redundant, i.e. differently composed communities perform similar functions (Müller et al. 2002, Langenheder et al. 2005, Sjöstedt et al. 2012). However, changes in community composition can also affect rates of ecosystem functioning 
(Findlay et al. 2003), suggesting that at least some microbial taxa are functionally dissimilar (Allison \& Martiny 2008). In order to reconcile these seemingly opposing findings, the effect of disturbance on community function has been suggested to depend on the function measured (Langenheder et al. 2005) and the type of disturbance (Bressan et al. 2008).

Here, we sought to identify whether differences in diversity and composition of bacterioplankton communities from the Gulf of Trieste affected functionality. Since heterotrophic bacteria are an important link between dissolved organic carbon (DOC) and higher trophic levels in marine waters, we used DOC utilization as a proxy for community function. Quantity and quality of DOC have strong impacts on bacterioplankton community composition (Pinhassi et al. 1999, Crump et al. 2003, Eiler et al. 2003), and there is evidence that different phylogenetic groups preferably utilize certain components of the bulk DOC pool (Martinez et al. 1996, Cottrell \& Kirchman 2000, Riemann et al. 2000). However, it has also been suggested that generalist bacteria, capable of metabolizing a wide variety of organic carbon compounds, are important members of the bacterioplankton community (Mou et al. 2008, Gómez-Consarnau et al. 2012). We applied continuous seawater cultures to manipulate the composition and diversity of bacterioplankton communities from the Gulf of Trieste, northern Adriatic Sea. In this approach, species vulnerable to a treatment are progressively lost from indigenous communities. This is comparable to natural systems where a disturbance hampers some species and selects for adapted species (Müller et al. 2002, Griffiths et al. 2004). The confined bacterial communities were manipulated by sequential increasing environmental stress by decreasing the temperature, adding phosphate and lowering the oxygen level. The changed conditions represent environmental drivers that we expect to regularly affect bacterioplankton assemblages indigenous to the Gulf of Trieste. Subsequently, the abilities of the manipulated communities to utilize DOC were compared to that of the diverse indigenous community.

\section{MATERIALS AND METHODS}

\section{Location and experimental setup}

The Gulf of Trieste is the northernmost part of the Adriatic sea (NE Mediterranean Sea). The area is characterized by shallow waters with large fluctuations in salinity (from 32.8 to 36.7 ) and temperature (from 9 to $25^{\circ} \mathrm{C}$ ). The concentration of phosphorus is generally low and limits growth of phytoplankton and bacterioplankton (Fajon et al. 1999, Malej et al. 2003), and oxygen depletion below the thermocline is observed almost every year (Turk et al. 2001).

Filtered seawater inoculated with an indigenous natural bacterial assemblage was exposed to decreased temperature (Stress 1), decreased temperature and phosphate addition (Stress 2) or decreased temperature, phosphate addition and lowered oxygen level (Stress 3) in a continuous culture setup (Sjöstedt et al. 2012). Moreover, the setup included an incubation with only the stress conferred by confinement, named 'Control'. Effects of increasing environmental stress on bacterial community composition, diversity and functionality were identified by comparison to the indigenous bacterial community (i.e. the inoculum). Bacterial community composition and diversity, in the inoculum and in the 4 cultures after $14 \mathrm{~d}$ of incubation, was analyzed using DGGE and 454-pyrosequencing of 16S rRNA genes. The ability to utilize natural DOC was examined in DOC-utilization assays.

\section{Preparation of medium and inoculum for the continuous cultures}

Seawater was collected at $3 \mathrm{~m}$ depth, $2.3 \mathrm{~km}$ from shore in the Gulf of Trieste, Northern Adriatic $\left(45^{\circ} 33^{\prime} \mathrm{N}_{;} 13^{\circ} 33^{\prime} \mathrm{E}\right)$, using 71 Niskin bottles mounted on a rosette. Seawater used as medium in the continuous seawater cultures was collected on 25 August and inoculum on 8 September 2009. The seawater temperature was $24.9^{\circ} \mathrm{C}$ and $22.7^{\circ} \mathrm{C}$, and the salinity was 36.35 and 36.06 , respectively. Seawater was kept in acid-washed polycarbonate bottles and processed within $2 \mathrm{~h}$. Seawater used as medium was filtered through a $0.2 \mu \mathrm{m}$ capsule filter (Acropak, Pall) using a peristaltic pump and autoclaved twice before the assembly of the continuous culture system. The seawater inoculum was gravity filtered (once through $3.0 \mu \mathrm{m}$, twice through $0.6 \mu \mathrm{m}$ filters; polycarbonate, Whatman) and stored at $4^{\circ} \mathrm{C}$ for $\sim 12 \mathrm{~h}$ before inoculation of the continuous seawater cultures.

\section{Setup of continuous seawater cultures}

The 4 continuous cultures were run for $14 \mathrm{~d}$ in the dark at a dilution rate of $1 \mathrm{~d}^{-1}$ and are referred to as Control (in situ temperature, $\left.24^{\circ} \mathrm{C}\right)$, Stress $1\left(16^{\circ} \mathrm{C}\right)$, Stress $2\left(16^{\circ} \mathrm{C}\right.$ plus phosphate) and Stress $3\left(16^{\circ} \mathrm{C}\right.$, plus phosphate, plus lowered oxygen level). Stress 2 and 3 were amended with $\mathrm{KH}_{2} \mathrm{PO}_{4}\left(0.5 \mu \mathrm{mol}{ }^{-1}\right.$ final 
conc.). In Stress 3, the oxygen level was lowered by bubbling with nitrogen gas (0.5 bar) instead of air (see below). The systems were assembled and autoclaved before 0.51 inoculum was added to a 11 cultivation bottle. The medium (one 101 container per culture) was fed drop-wise through a glass tube to prevent back growth, and filtered air produced small bubbles that served as a stirrer for the culture (Sjöstedt et al. 2012). At the end of the experiment, the oxygen concentration in the continuous cultures was measured using a combined conductivity and dissolved oxygen sensor (Con Ox Multi 350i WTW).

\section{DOC degradation experiments}

The capacity to utilize natural DOC was used to measure community functionality. This was compared for the inoculum and the bacterial communities in the 4 continuous cultures after $14 \mathrm{~d}$ of incubation. Microbial DOC degradation was measured as the decrease in DOC over time in triplicate batch incubations containing sterile filtered seawater amended with a bacterial inoculum and inorganic nitrogen and phosphate (10 $\mu_{\mathrm{mol} \mathrm{l}}^{-1} \mathrm{KNO}_{3}$ and $0.5 \mu \mathrm{mol} \mathrm{l^{-1 }} \mathrm{KH}_{2} \mathrm{PO}_{4}$, final conc.). Seawater used as medium (collected at the same time as medium for the continuous cultures) was filtered through $0.2 \mu \mathrm{m}$, Supor filters (Pall) using a vacuum pump, kept in acid-washed polycarbonate bottles, autoclaved twice and then stored at $4{ }^{\circ} \mathrm{C}$ until inoculation. An aliquot of $900 \mathrm{ml}$ of seawater medium was inoculated with $100 \mathrm{ml}$ of filtered inoculum (prepared as for the continuous cultures). DOC batch cultures were started in triplicates from the inoculum (start of experiment) and from the bacterial community in each continuous culture (end of experiment) and were incubated in the dark for $9 \mathrm{~d}$. The batch cultures started from the inoculum were incubated at in situ temperature $\left(24^{\circ} \mathrm{C}\right)$, and the other cultures were incubated at the same temperature as the respective continuous culture. Duplicate samples for DOC analysis were collected daily from the batch cultures. The samples $(10 \mathrm{ml})$ were filtered through acid-washed $0.2 \mu \mathrm{m}$ Supor filters (Pall) into polypropylene tubes (Falcon), acidified with $170 \mu \mathrm{l}$ of $1 \mathrm{~mol} \mathrm{l}^{-1} \mathrm{HCl}$ and stored at $4^{\circ} \mathrm{C}$ until analysis. All materials in contact with the samples were carefully acid-rinsed prior to use. Samples were analyzed on a Shimadzu TOC-5000 high-temperature catalytic oxidation instrument using potassium hydrogen phthalate as the standard substance. Normal distribution of the DOC data from the DOC utilization assays was confirmed using the Shapiro-Wilk normality test, and differences were subse- quently examined by ANOVA followed by a Tukey's post-hoc test.

Samples for bacterial enumeration were taken daily and fixed and stored as described below.

\section{Enumeration of bacteria, viruses and flagellates}

Samples for bacterial and viral abundance in the continuous cultures were obtained daily, fixed with glutaraldehyde ( $1 \%$ final conc.) and stored at $-80^{\circ} \mathrm{C}$. Duplicate samples were taken from all cultures at the last day of sampling and generally varied less than $5 \%$. Bacteria were stained with SYTO 13 (Molecular Probes) and viruses with SYBR Green 1 (Molecular Probes) and counted on a FACSCalibur flow cytometer (Becton Dickinson) according to published protocols (Troussellier et al. 1999, Brussaard 2004) using fluorescent beads (True counts, Becton Dickinson) to calibrate the flow rate.

On Days 6, 10 and 14, samples were examined to verify that flagellates were not present in the cultures. A total of $30 \mathrm{ml}$ of sample was fixed with formaldehyde (3\% final conc.) and filtered onto $1 \mu \mathrm{m}$ black polycarbonate filters. Cells were stained with primulin $\left(20 \mu \mathrm{g} \mathrm{ml}^{-1}\right)$ (Chrzanowski \& Simek 1990), and filters were examined for flagellates using epifluorescence microscopy (Zeiss Axioplan). No flagellates were observed.

\section{DNA extraction}

Samples for analysis of bacterial community composition were collected from the continuous cultures every day. Approximately $400 \mathrm{ml}$ sample (collected in a sterile bottle from the outflow of the continuous culture) was filtered onto $0.2 \mu \mathrm{m}$ Supor filters $(25 \mathrm{~mm}$ diam., Pall), which were stored at $-20^{\circ} \mathrm{C}$ until extraction. DNA was extracted using an enzyme/phenolchloroform protocol (Riemann et al. 2000) but with a $30 \mathrm{~min}$ lysozyme digestion ( $5 \mathrm{mg} \mathrm{ml}^{-1}$ final conc.) at $37^{\circ} \mathrm{C}$ and an overnight Proteinase $\mathrm{K}$ digestion (100 $\mu \mathrm{g} \mathrm{ml}^{-1}$ final conc.) at $55^{\circ} \mathrm{C}$ (Boström et al. 2004). DNA was re-suspended in TE buffer and quantified using PicoGreen (Molecular Probes).

\section{Community structure and succession as analyzed by denaturing gradient gel electrophoresis (DGGE)}

We used DGGE as a means of comparing community structures based on the dominant phylotypes 
(representing $>1 \%$ of the community; Muyzer et al. 1993) as well as to follow community succession in selected cultures over time. Bacterial 16S rRNA genes were PCR-amplified using primers GC341F and $907 \mathrm{R}$ as previously described (Sjöstedt et al. 2012), and the products were quantified using PicoGreen. Then, $60 \mathrm{ng}$ of PCR product was analyzed by DGGE using the D Gene System (Bio-Rad) at $60^{\circ} \mathrm{C}$ for $6 \mathrm{~h}$ at $150 \mathrm{~V}$. Gels were stained with SYBR Gold (Molecular Probes). Based on the presence/absence of DGGE bands, a dendrogram was constructed by the software Quantity One 4.6.2 (Bio-Rad) using the Dice coefficient and cluster analysis by the unweighted-pair group method using arithmetic average. The Dice similarity coefficient represents pairwise comparisons of the DGGE profiles. It is calculated based on the formula $\mathrm{D}_{\mathrm{sc}}=[2 j /(a+b)]$, where $a$ is the number of DGGE bands in Lane $1, b$ is the number of DGGE bands in Lane 2, and $j$ is the number of common DGGE bands in Lanes 1 and 2 (Fromin et al. 2002).

\section{4-pyrosequencing of bacterial communities}

454-pyrosequencing of 16S rRNA genes (including the variable V4 to V6 regions) was used to compare the community composition, at phylum and family level, between the inoculum and the end communities in the continuous cultures. Sequence data were also used to examine how bacterial diversity responded to the increasing environmental stress. A primer cocktail containing the degenerate primers 530F (5'-GTG CCA GCM GCN GCG GTA-3'; Dowd et al. 2008), with TA added at the 3-prime end to increase specificity, and 1061R (5'-CRR CAC GAG CTG ACG AC-3'; Andersson et al. 2008) labeled with specific hexamers for each sample was used for the amplification. The PCR products were gel purified (QIAquick Gel Extraction Kit, Qiagen), concentrated (QIAquick PCR Purification Kit, Qiagen) and quantified before being mixed in equimolar amounts. Addition of adaptor and pyrosequencing (Roche GS FLX TITANIUM platform) on half of a plate was performed at LGC Genomics (Germany) according to the manufacturer's instructions.

The 454-pyrosequencing resulted in 488561 sequences. Sequences < $150 \mathrm{bp}$, sequences with undetermined nucleotides or sequences not containing the correct primer sequence were removed using the Ribosomal Database Project (RDP) pyrosequencing pipeline (http://pyro.cme.msu.edu/). Forward primer sequences were also removed in this step. The re- maining sequences (383 571) were clustered at 97\% similarity using cropLINUX (Hao et al. 2011), which uses a Gaussian Mixture model and can automatically determine the best clustering result for $16 \mathrm{~S}$ rRNA sequences at different phylogenetic levels without setting a cut-off threshold, like hierarchical clustering does (Hao et al. 2011). Using cropLINUX, 1327 clusters (operational taxonomic units [OTUs]) were produced. These were further screened for chimeric sequences at the OTU level using ChimeraSlayer (Haas et al. 2011), and 115 chimeric OTUs (7208 sequences) were removed. The Greengenes online tool (http://greengenes.lbl.gov) was used to align and classify the sequences. This tool gives taxonomic results from Greengenes, RDP and National Center for Biotechnology Information (NCBI). In most cases, all 3 databases gave the same result; however, when not consistent, Greengenes was used for the classification since it was also used for the alignment. A total of 229 OTUs (1411 sequences) could not be aligned, and 11 OTUs (148 sequences) could not be classified. These OTUs were removed from the data set. Singletons were removed (571 OTUs/ sequences), leaving a final number of 630 OTUs (374804 sequences).

Maximum likelihood trees were inferred with the aid of the RAxML software (v. 7.2.8) using the GTRGAMMA model with default settings (Stamatakis 2006). Community distance analysis was performed using the unweighted UniFrac measure (http://bmf2.colorado.edu/fastunifrac/) (Lozupone \& Knight 2005), which is a qualitative analysis using presence/absence of data to compare community composition. The distance between 2 communities is calculated as the fraction of branch length that leads to descendants in either, but not both, of 2 communities (Lozupone et al. 2007). To assess whether the UniFrac distance metrics between communities were significant, Unifrac significance and p-value significance tests were done as implemented in the UniFrac program (Lozupone \& Knight 2005). Each pair of samples was tested against each other, and the $\mathrm{p}$-values were corrected for multiple comparisons using Bonferroni correction. Based on the pairwise UniFrac values, a principal coordinates analysis was performed to examine the similarities among samples.

To visualize the distribution of the most abundant OTUs between the different treatments, a maximum likelihood tree with a heatmap was constructed. The tree was based on 121 OTUs, each represented by >100 sequences across samples, 49 reference sequences from other studies and 1 outgroup sequence 
from the Aquifex genus. The tree was constructed as described above, and the heatmap was constructed using iTOL (http://itol.embl.de/).

Random re-sampling of 15000 sequences per sample was performed using a script developed in MAT$\mathrm{LAB}$ to normalize the relative abundance of sequences between samples. Rarefaction curves (Analytical Rarefaction 1.3, www.uga.edu/strata/software/index. html), $C_{A C E}$ coverage estimate (Chao et al. 1993), $S_{\text {Chao1 }}$ richness (Chao 1984) and the Shannon diversity index (Shannon 1948) were calculated using the re-sampled data set.

\section{Nucleotide sequence accession numbers}

DNA sequences have been deposited in the NCBI Sequence Read Archive under accession number SRA055085.

\section{RESULTS AND DISCUSSION}

The main aim of the present study was to examine whether differences in bacterial community composition and diversity would affect function. Increasing environmental stress was applied in continuous bacterioplankton cultures to obtain communities differing in diversity and composition relative to in situ characteristics. We selected stress factors, here defined as perturbations anticipated to affect bacterial communities, that regularly affect bacterioplankton assemblages indigenous to the Gulf of Trieste. In addition, confinement in itself (the Control) was expected to have a major effect on bacterial diversity and composition. The selected stress factors (decrea-

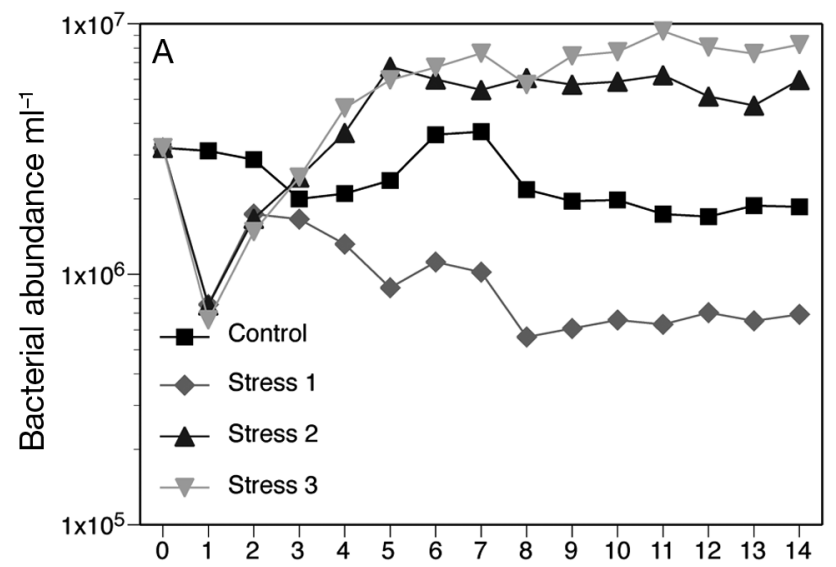

sing temperature, added phosphate and lowered oxygen level) are known to affect bacterial growth. For instance, lowered temperature may negatively affect bacterioplankton growth rate (e.g. Pomeroy et al. 1991, Wiebe et al. 1992, Kirchman \& Rich 1997), whereas addition of phosphate would conceivably cause major community compositional successions in the phosphorus-limited Gulf of Trieste (Fajon et al. 1999, Malej et al. 2003). Finally, the manipulated communities were examined for their functionality, proxied by the ability to utilize bulk DOC, which is a key process in marine biogeochemistry and an important subsidy to higher trophic levels in aquatic systems. Our study demonstrates that confinement and the selected stress factors caused a reduced bacterial diversity and changed composition relative to the inoculum. However, DOC degradation did not differ significantly from the inoculum, suggesting this community function to be resilient to environmental stress and diversity loss and to be driven by functionally redundant taxa.

\section{Effect of treatments on bacterial and viral abundance}

Since the main objective of the 4 continuous cultures was to construct bacterial communities differing in structure and diversity, not to identify specific and un-replicated effects of temperature, phosphate or oxygen, the effects of the manipulations on other parameters are only briefly addressed below. The bacterial abundance was $3.2 \times 10^{6}$ cells ml $^{-1}$ at the start of the experiment but then decreased in all treatments, except for the Control, during the first day (Fig. 1A). The addition of phosphate resulted in

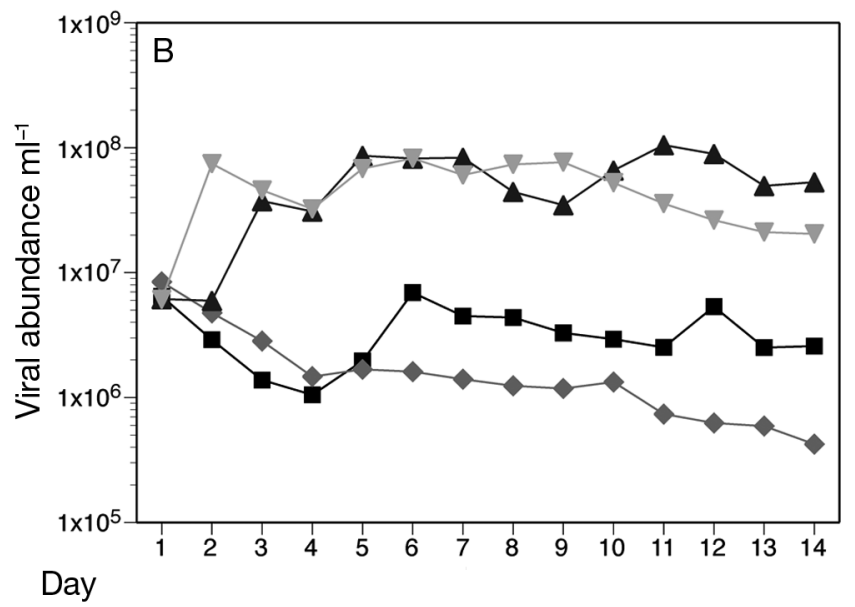

Fig. 1. (A) Bacterial and (B) viral abundance in the 4 continuous cultures. Control $\left(24^{\circ} \mathrm{C}\right)$; Stress $1\left(16^{\circ} \mathrm{C}\right)$; Stress $2\left(16^{\circ} \mathrm{C}\right.$ and elevated phosphate); Stress $3\left(16^{\circ} \mathrm{C}\right.$, elevated phosphate, and lowered oxygen level) 
higher phosphate concentrations and lower nitrogen concentrations in Stress 2 and 3 relative to the Control and Stress 1 (Table 1) and is probably related to a change in the system from phosphorus to nitrogen limitation. The addition of phosphate seemed to overrule the negative effect of lowered temperature and stimulated bacterial abundance. The oxygen concentrations in the Control and Stress 1 and 2 treatments were comparable to that in the inoculum. In Stress 3, the oxygen concentration was reduced to $1.37 \mathrm{mg} \mathrm{ml}^{-1}$, corresponding to $17 \%$ oxygen saturation (Table 1). However, the decreased oxygen level did not significantly affect bacterial abundance. After $\sim 8 \mathrm{~d}$, bacterial abundance stabilized and varied by $14 \%$ in Stress 3 but $<10 \%$ in the other treatments during the last week (Fig. 1A). The stabilization of bacterial abundance suggests establishment of communities adapted to the manipulated conditions. Viral abundance roughly mirrored bacterial abundance and reached highest levels in Stress 2 and 3, but showed higher variation than bacterial abundance during the last week of sampling (Fig. 1B).

\section{Effect of manipulations on bacterial community composition and diversity}

DGGE of 16S rRNA genes showed that community composition changed considerably, with bands disappearing and appearing over time indicating a change in abundant phylotypes during the experiment (shown for Stress 3 in Fig. S1 in the Supplement at www.int-res.com/articles/suppl/a071p015 _supp.pdf). However, as suggested by the stabilization of bacterial abundances, similar banding patterns and number of bands were obtained toward the end of the incubation, indicating a stabilization and establishment of communities adapted to the manipulated conditions. When the different treatments were compared, more discernible bands were observed in the inoculum than in the treatment samples from the last day (data not shown). Based on a dendrogram constructed from the banding patterns, the inoculum and the Control formed one cluster, whereas Stress 1 to 3 formed a second cluster. However, the similarity analysis is only based on the most dominant phylotypes, and similarities between all treatments were rather low, varying from around 20 to $40 \%$ (Fig. 2).

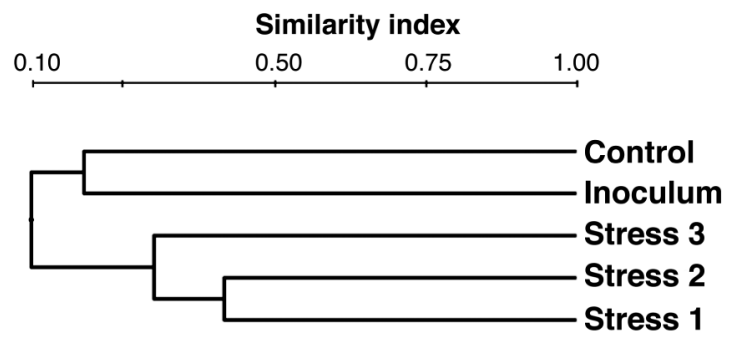

Fig. 2. Dendrogram comparing bacterial community composition in the inoculum (Day 0) and in different continuous cultures (Day 14) analyzed by DGGE. Control $\left(24^{\circ} \mathrm{C}\right)$; Stress $1\left(16^{\circ} \mathrm{C}\right)$; Stress $2\left(16^{\circ} \mathrm{C}\right.$ and elevated phosphate); Stress $3\left(16^{\circ} \mathrm{C}\right.$, elevated phosphate, and lowered oxygen level)

Based on 454-pyrosequencing, all except 4 of the dominant OTUs (representing $\geq 100$ sequences) were detected in the inoculum. Fifty of the OTUs were only detected in the inoculum, and 1 OTU was only in the Control, whereas the rest of the OTUs were shared between at least 2 communities (Fig. S2 in the Supplement). Several rare OTUs $(<0.1 \%$ of the reads) in the inoculum became abundant $(>5 \%$ of the reads) in at least one of the treatments. These rare OTUs are probably members of the rare biosphere that proliferated in response to the changed environmental conditions (Pedrós-Alió 2006, Sjöstedt et al. 2012). Upon confinement in the continuous culture, OTUs only detected in the inoculum decreased in abundance to below the detection limit. The abundance of most of these OTUs in the inoculum was below $1 \%$, and it is possible that they were not actively growing (dormant or dead) and therefore flushed out of the continuous culture. Alternatively, optimal growth conditions were not met in the continuous cultures. Nevertheless, as expected, much fewer OTUs were detected in the 4 manipulations (including the Control) relative to the inoculum. 
The rarefaction curves for all samples except for the inoculum were in a near-plateau phase (Fig. S3 in the Supplement). Nevertheless, according to the $\mathrm{C}_{\mathrm{ACE}}$ coverage estimate, our sampling only detected 29 to $43 \%$ of the OTU richness in the samples, which is consistent with the results from Chao1 richness estimator giving a higher probable total number of OTUs than the number of observed OTUs. The number of OTUs in the inoculum (502 OTUs) was much higher than in the continuous cultures after $14 \mathrm{~d}$ of
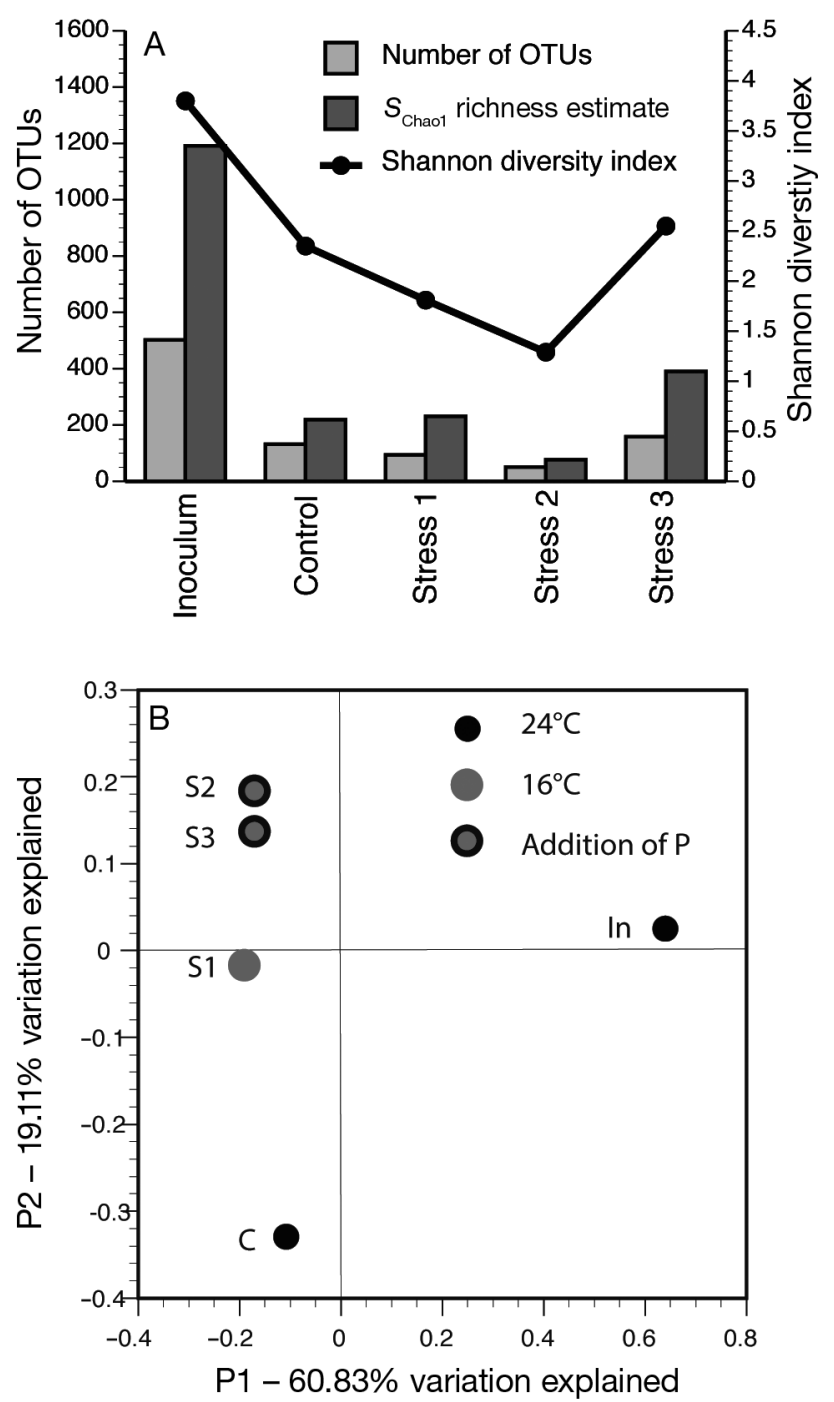

Fig. 3. (A) The number of OTUs, $S_{\text {Chao1 }}$ richness estimates (estimated number of OTUs) and Shannon diversity indices for the continuous cultures after $14 \mathrm{~d}$ incubation and for the inoculum as analyzed by 454-pyrosequencing. (B) Principal coordinates analysis of the same samples using unweighted UniFrac. Shown is a plot of the first 2 principal coordinate axes. In: inoculum; C: Control $\left(24^{\circ} \mathrm{C}\right)$; S1: Stress $1\left(16^{\circ} \mathrm{C}\right)$; S2: Stress $2\left(16^{\circ} \mathrm{C}\right.$ and elevated phosphate); S3: Stress $3\left(16^{\circ} \mathrm{C}\right.$, elevated phosphate and lowered oxygen level) incubation (51 to 158 OTUs; Fig. 3A). The pattern was the same both for the observed and predicted number of OTUs and for the Shannon diversity index, with highest richness and diversity observed in the inoculum and decreased levels in all treatments, including the Control (Fig. 3A). The high diversity in the inoculum is comparable to previous observations from the Mediterranean Sea (e.g. Pommier et al. 2010), and a decreased diversity as a consequence of confinement (Massana et al. 2001, Sjöstedt et al. 2012) and environmental stress (Reice 1985, Berga et al. 2012) is consistent with other cultivation studies. The slightly higher diversity in Stress 3 may be due to proliferation of diverse facultative anaerobic bacteria, a trait that does not appear linked to phylogeny (Riemann \& Azam 2002). Hence as expected, a much lower bacterial diversity was observed in the 4 manipulations (including the Control) relative to the inoculum.

In agreement with the DGGE results, Unifrac analysis showed that all communities except Stress 2 and 3 were significantly different from each other $(\mathrm{p} \leq$ 0.05, according to UniFrac significance and/or $p$ value significance tests). On the principal coordinates analysis (resulting from pairwise UniFrac values), Stress 2 and 3 clustered together, indicating that phosphate availability is an important selective driver for bacterial community composition (Fig. 3B). This is consistent with previous findings showing that specific bacterioplankton groups are adapted to low phosphate concentrations, e.g. SAR11 and Prochlorococcus (Martiny et al. 2006, Sowell et al. 2009). In addition, phosphate availability affected the viral abundance (Fig. 1B), which may indirectly influence bacterial community composition through virusmediated mortality (Scanlan \& Wilson 1999). Most notably, Gammaproteobacteria accounted for 70 to $90 \%$ of the sequences in the treatments but only $\sim 30 \%$ in the inoculum and the Control. Major differences between the treatments were evident at the family level, particularly within Gammaproteobacteria. The inoculum was dominated by Alpha- and Gammaproteobacteria and Bacteroidetes (Fig. S4A in the Supplement), which is consistent with existing data from the Gulf of Trieste in late summer (Tinta 2011). Within Gammaproteobacteria, the inoculum was dominated by Pseudomonadaceae and the Control by Vibrionaceae (Fig. S4B). In Stress 1, the gammaproteobacterial Families Moraxellaceae and Alteromonadaceae were dominant. Interestingly, the Family Moraxellaceae consists of psychrophilic or mesophilic bacteria (Rossau et al. 1991), which may explain their selective growth at lowered tempera- 
ture. In Stress 2 and 3, the Families Oceanospirillaceae and Alteromonadaceae (genus Microbulbifer in Stress 2 and Alteromonas in Stress 3) were prominent (Fig. S4B). Both Alteromonas and Vibrio spp. have previously been observed to become enriched upon confinement (Eilers et al. 2000). Hence as expected, the 4 manipulations (including the Control) differed markedly in composition relative to the inoculum.

\section{Effect of bacterial community composition and diversity on functionality}

Community functionality, proxied by the consumption of natural DOC over $9 \mathrm{~d}$, was investigated in batch cultures of sterile seawater amended with bacteria from the inoculum and the continuous cultures
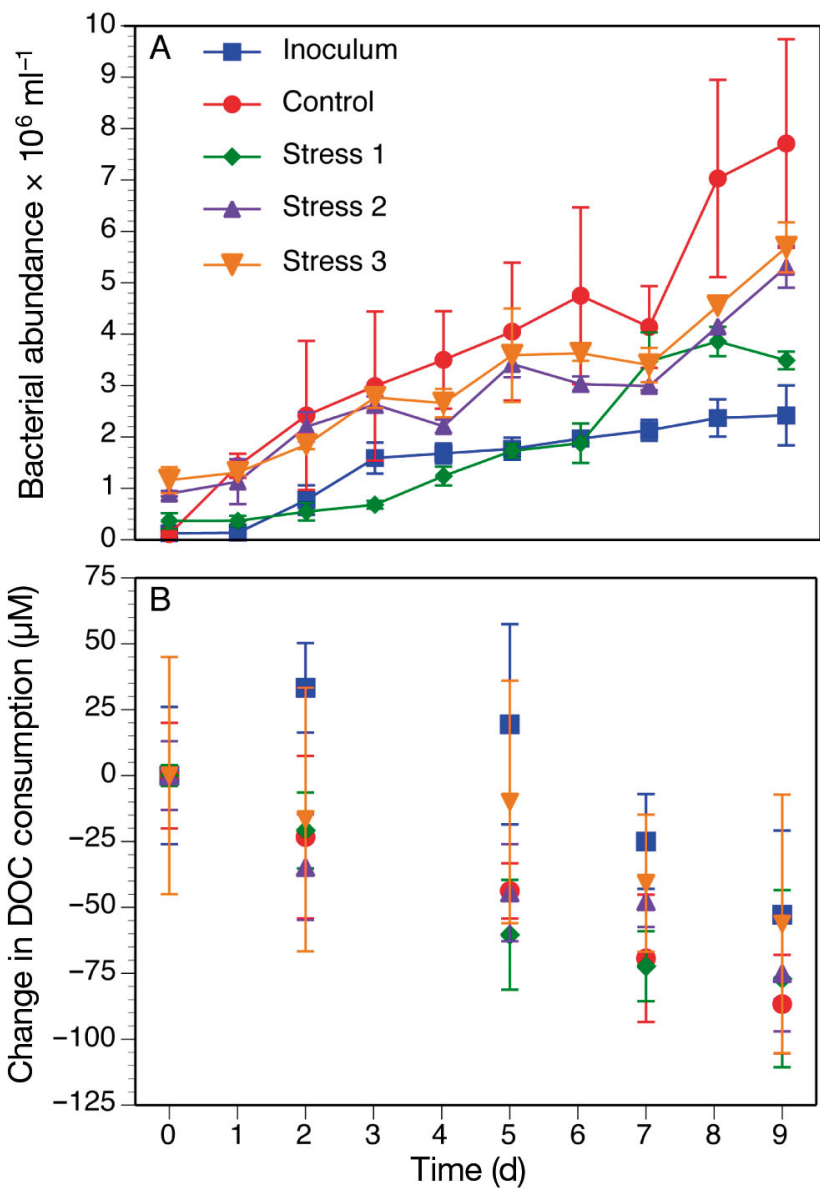

Fig. 4. Dynamics in the DOC batch cultures. (A) Bacterial abundances. Values are averages from triplicate batch cultures. (B) Change in DOC consumption. Values are averages of duplicate samples from triplicate batch cultures, and error bars indicate standard deviations. Control $\left(24^{\circ} \mathrm{C}\right)$; Stress 1 $\left(16^{\circ} \mathrm{C}\right)$; Stress $2\left(16^{\circ} \mathrm{C}\right.$ and elevated phosphate); Stress 3 $\left(16^{\circ} \mathrm{C}\right.$, elevated phosphate and lowered oxygen level) after $14 \mathrm{~d}$ incubation. Bacterial abundance increased in all treatments, but with a short lag phase in all treatments except the Control (Fig. 4A). The initial concentration of DOC in the incubators $(223 \pm 35 \mu \mathrm{M})$ was reduced by 25 to $34 \%$, and despite large differences in community composition (Fig. 3B \& Fig. S4) and diversity (Fig. 3A), no significant differences in DOC utilization were observed after $9 \mathrm{~d}$ of incubation (Fig. 4B). Also, no significant differences were found between the treatments (Control or Stress 1 to 3) during any of the earlier time points. However, at Day 5, there was a significant difference between the inoculum and Stress 1, and at Day 7, the DOC concentration was significantly higher in the inoculum than in Stress 1 and Control ( $\mathrm{p} \leq 0.05)$.

We used DOC degradation as a proxy for community function because, although coarse, this ability appears to us to be more ecologically relevant than the targeting of specific functions. Consistent with our findings, some previous studies have reported no linkage between community structure and broadscale functional performance in incubations (e.g. Langenheder et al. 2005, 2006, Reinthaler et al. 2005), probably because processes carried out by a limited range of microorganisms are more sensitive to perturbations than processes carried out by a wide range of microorganisms (Griffiths et al. 2004, Girvan et al. 2005). Studies of soil microbial communities suggest that ecosystem functioning is independent of species diversity as long as all functional groups are represented (Griffiths et al. 2000, Müller et al. 2002), and ecosystems with high species richness may therefore be insensitive to diversity variations (Naeem 1998). This is consistent with our observation that dramatic reductions in diversity of Adriatic bacterioplankton or differences in community composition did not reduce a broad-scale function like DOC utilization. Disturbance-induced changes in community composition have, however, been suggested to modify the competitive interactions among taxa resulting in a switch to new substrates (Berga et al. 2012). Whether the constant DOC utilization is a result of switching to new substrates or true functional redundancy cannot be separated without detailed examination of the utilization patterns of single carbon sources. Therefore, while a high bacterioplankton diversity is likely essential for maintaining specific functions during environmental perturbation (e.g. in a dynamic coastal environment like the Gulf of Trieste), oscillations in overall DOC exploitation are not linked to community succession or diversity but rather are governed by factors limiting bacterial growth in general. 
Acknowledgements. We thank T. Makovec and M. Tadejevic, Marine Biology station, Piran, for assistance with sampling, B. Canbäck for assistance with sequence analysis, and A. Tunlid for valuable comments during the initial phase of the project. This work was supported by grant 621-20085385 from the Swedish Research Council to Å.H.

\section{LITERATURE CITED}

Allison SD, Martiny JB (2008) Resistance, resilience, and redundancy in microbial communities. Proc Natl Acad Sci USA 105:11512-11519

> Andersson AF, Lindberg M, Jakobsson H, Bäckhed F, Nyrén P, Engstrand L (2008) Comparative analysis of human gut microbiota by barcoded pyrosequencing. PLoS ONE 3:e2836

> Berga M, Székely AJ, Langenheder S (2012) Effects of disturbance intensity and frequency on bacterial community composition and function. PLoS ONE 7:e36959

> Boström HK, Simu K, Hagström Å, Riemann L (2004) Optimization of DNA extraction for quantitative marine bacterioplankton community analysis. Limnol Oceanogr Methods 2:365-373

Bowen JL, Ward BB, Morrison HG, Hobbie JE, Valiela I, Deegan LA, Sogin ML (2011) Microbial community composition in sediments resists perturbation by nutrient enrichment. ISME J 5:1540-1548

Bressan M, Mougel C, Dequiedt S, Maron P, Lemanceau P, Ranjard L (2008) Response of soil bacterial community stucture to successive perturbations of different types and intensities. Environ Microbiol 10:2184-2187

- Brussaard CP (2004) Optimization of procedures for counting viruses by flow cytometry. Appl Environ Microbiol 70:1506-1513

Chao A (1984) Nonparametric estimation of the number of classes in a population. Scand J Stat 11:265-270

> Chao A, Ma MC, Yang M (1993) Stopping rules and estimation for recapture debugging with unequal failure rates. Biometrika 80:193-201

> Chrzanowski TH, Simek K (1990) Prey-size selection by freshwater flagellated protozoa. Limnol Oceanogr 35: 1429-1436

Cottrell MT, Kirchman DL (2000) Natural assemblages of marine Proteobacteria and members of the CytophagaFlavobacter cluster consuming low- and high-molecularweight dissolved organic matter. Appl Environ Microbiol 66:1692-1697

Crump BC, Kling GW, Bahr M, Hobbie JE (2003) Bacterioplankton community shifts in an Arctic lake correlate with seasonal changes in organic matter source. Appl Environ Microbiol 69:2253-2268

> Dowd SE, Sun Y, Wolcott RD, Domingo A, Carroll JA (2008) Bacterial tag-encoded FLX amplicon pyrosequencing (bTEFAP) for microbiome studies: bacterial diversity in the ileum of newly weaned Salmonella-infected pigs. Foodborne Pathog Dis 5:459-472

> Eiler A, Langenheder S, Bertilsson S, Tranvik LJ (2003) Heterotrophic bacterial growth efficiency and community structure at different natural organic carbon concentrations. Appl Environ Microbiol 69:3701-3709

Eilers H, Pernthaler J, Amann R (2000) Succession of pelagic marine bacteria during enrichment: a close look at cultivation-induced shifts. Appl Environ Microbiol 66: 4634-4640
Fajon C, Cauwet G, Lebaron P, Terzic S and others (1999) The accumulation and release of polysaccharides by planktonic cells and the subsequent bacterial response during a controlled experiment. FEMS Microbiol Ecol 29: 351-363

Findlay SEG, Sinsabaugh RL, Sobczak WV, Hoostal M (2003) Metabolic and structural response of hyporheic microbial communities to variations in supply of dissolved organic matter. Limnol Oceanogr 48:1608-1617

> Fromin N, Hamelin J, Tarnawski S, Roesti D and others (2002) Statistical analysis of denaturing gel electrophoresis (DGE) fingerprinting patterns. Environ Microbiol 4: $634-643$

Girvan MS, Campbell CD, Killham K, Prosser JI, Glover LA (2005) Bacterial diversity promotes community stability and functional resilience after perturbation. Environ Microbiol 7:301-313

Gómez-Consarnau L, Lindh MV, Gasol JM, Pinhassi J (2012) Structuring of bacterioplankton communities by specific dissolved organic carbon compounds. Environ Microbiol 14:2361-2378

- Griffiths BS, Ritz K, Bardgett RD, Cook R and others (2000) Ecosystem response of pasture soil communities to fumigation-induced microbial diversity reductions: an examination of the biodiversity-ecosystem function relationship. Oikos 90:279-294

> Griffiths BS, Kuan HL, Ritz K, Glover LA, McCaig AE, Fenwick C (2004) The relationship between microbial community structure and functional stability, tested experimentally in an upland pasture soil. Microb Ecol 47: $104-113$

> Haas BJ, Gevers D, Earl AM, Feldgarden M and others (2011) Chimeric 16S rRNA sequences formation and detection in Sanger and 454-pyrosequencing PCR amplicons. Genome Res 21:494-504

Hao X, Jiang R, Chen T (2011) Clustering 16S rRNA for OTU prediction: a method of unsupervised Bayesian clustering. Bioinformatics 27:611-618

Kirchman DL, Rich JH (1997) Regulation of bacterial growth rates by dissolved organic carbon and temperature in the equatorial Pacific Ocean. Microb Ecol 33: 11-20

> Langenheder S, Lindström ES, Tranvik LJ (2005) Weak coupling between community composition and functioning of aquatic bacteria. Limnol Oceanogr 50:957-967

> Langenheder S, Lindström ES, Tranvik LJ (2006) Structure and function of bacterial communities emerging from different sources under identical conditions. Appl Environ Microbiol 72:212-220

> Lozupone C, Knight R (2005) UniFrac: a new phylogenetic method for comparing microbial communities. Appl Environ Microbiol 71:8228-8235

- Lozupone CA, Hamady M, Kelley ST, Knight R (2007) Quantitative and qualitative $\beta$ diversity measures lead to different insights into factors that structure microbial communities. Appl Environ Microbiol 73:1576-1585

Malej A, Mozetic P, Turk V, Terzic S, Ahel M, Cauwet G (2003) Changes in particulate and dissolved organic matter in nutrient-enriched enclosures from an area influenced by mucilage: the northern Adriatic Sea. J Plankton Res 25:949-966

Martinez J, Smith DC, Steward GF, Azam F (1996) Variability in ectohydrolytic enzyme activities of pelagic marine bacteria and its significance for substrate processing in the sea. Aquat Microb Ecol 10:223-230 
Martiny AC, Coleman ML, Chisholm SW (2006) Phosphate acquisition genes in Prochlorococcus ecotypes: Evidence for genome-wide adaptation. Proc Natl Acad Sci USA 103:12552-12557

Massana R, Pedrós-Alió C, Casamayor EO, Gasol JM (2001) Changes in marine bacterioplankton phylogenetic composition during incubation designed to measure biogeochemically significant parameters. Limnol Oceanogr 46: 1181-1188

$>$ Mou X, Sun S, Edwards RA, Hodson RE, Moran MA (2008) Bacterial carbon processing by generalist species in the coastal ocean. Nature 451:708-711

- Müller AK, Westergaard K, Christensen S, Sørensen SJ (2002) The diversity and function of soil microbial communities exposed to different disturbances. Microb Ecol 44:49-58

Murray AE, Preston CM, Massana R, Taylor LT, Blakis A, Wu K, DeLong EF (1998) Seasonal and spatial variability of bacterial and archeal assemblages in the coastal waters near Anvers Island, Antarctica. Appl Environ Microbiol 64:2585-2595

> Muyzer G, de Waal EC, Uitterlinden AG (1993) Profiling of complex microbial populations by denaturing gradient gel electrophoresis analysis of polymerase chain reaction-amplified genes coding for 16S rRNA. Appl Environ Microbiol 59:695-700

> Naeem S (1998) Species redundancy and ecosystem reliability. Conserv Biol 12:39-45

Pedrós-Alió C (2006) Marine microbial diversity: Can it be determined? Trends Microbiol 14:257-263

> Pinhassi J, Azam F, Hemphälä J, Long RA, Martinez J, Zweifel UL, Hagström Å (1999) Coupling between bacterioplankton species composition, population dynamics, and organic matter degradation. Aquat Microb Ecol 17: $13-26$

> Pomeroy LR, Wiebe WJ, Deibel D, Thompson RJ, Rowe GT, Pakulski JD (1991) Bacterial responses to temperature and substrate concentration during the Newfoundland spring bloom. Mar Ecol Prog Ser 75:143-159

> Pommier T, Canbäck B, Riemann L, Boström KH and others (2007) Global patterns of diversity and community structure in marine bacterioplankton. Mol Ecol 16: 867-880

Pommier T, Neal PR, Gasol JM, Coll M, Acinas SG, PedrósAlió C (2010) Spatial patterns of bacterial richness and evenness in the NW Mediterranean Sea explored by pyrosequencing of the 16S rRNA. Aquat Microb Ecol 61: 221-233

Reice SJ (1985) Experimental disturbance and the maintenance of species diversity in a stream community. Oecologia 67:90-97

Reinthaler T, Winter C, Herndl GJ (2005) Relationship between bacterioplankton richness, respiration and

Editorial responsibility: Josep Gasol,

Barcelona, Spain production in the southern North Sea. Appl Environ Microbiol 71:2260-2266

- Riemann L, Azam F (2002) Widespread N-acetyl-Dglucosamine uptake among pelagic marine bacteria and its ecological implications. Appl Environ Microbiol 68: 5554-5562

> Riemann L, Steward GF, Azam F (2000) Dynamics of bacterial community composition and activity during a mesocosm diatom bloom. Appl Environ Microbiol 66:578-587

$>$ Rossau R, Van Landschoot A, Gillis M, De Ley J (1991) Taxonomy of Moraxellaceae fam. nov., a new bacterial family to accommodate the genera Moraxella, Acinetobacter, and Psychrobacter and related organisms. Int J Syst Bacteriol 41:310-319

Scanlan DJ, Wilson WH (1999) Application of molecular techniques to addressing the role of $\mathrm{P}$ as a key effector in marine ecosystems. Hydrobiologia 401:149-175

Shade A, Read JS, Welkie DG, Kratz TK, Wu CH, McMahon KD (2011) Resistance, resilience and recovery: aquatic bacterial dynamics after water column disturbance. Environ Microbiol 13:2752-2767

Shannon C (1948) A mathematical theory of communication. Bell Syst Tech J 27:379-423

Sjöstedt J, Koch-Schmidt P, Pontarp M, Canbäck B and others (2012) Recruitment of members from the rare biosphere of marine bacterioplankton communities after environmental disturbance. Appl Environ Microbiol 78: 1361-1369

Sowell SM, Wilhelm LJ, Norbeck AD, Lipton MS and others (2009) Transport functions dominate the SAR11 metaproteome at low-nutrient extremes in the Sargasso Sea. ISME J 3:93-105

> Stamatakis A (2006) RAxML-VI-HPC: maximum likelihoodbased phylogenetic analyses with thousands of taxa and mixed models. Bioinformatics 22:2688-2690

Tinta T (2011) Bacterial community structure and function in the Gulf of Trieste with some application studies. PhD dissertation, University of Nova Gorica

Troussellier M, Courties C, Lebaron P, Servais P (1999) Flow cytometric discrimination of bacterial populations in seawater based on SYTO 13 staining of nucleic acids. FEMS Microbiol Ecol 29:319-330

Turk V, Mozetic P, Malej A (2001) Seasonal variability in phytoplankton and bacterioplankton distribution in the semi-enclosed temperate gulf (Gulf of Trieste, Adriatic Sea). Ann Ser Hist Nat 11:53-64

Werner JJ, Knights D, Garcia ML, Scalfone NB and others (2011) Bacterial community structure are unique and resilient in full-scale bioenergy systems. Proc Natl Acad Sci USA 108:4158-4163

- Wiebe WJ, Sheldon J, Pomeroy LR (1992) Bacterial growth in the cold: evidence for an enhanced substrate requirement. Appl Environ Microbiol 58:359-364

Submitted: May 26, 2013; Accepted: September 4, 2013 Proofs received from author(s): November 6, 2013 